\title{
DNA repair gene expressions are related to bone marrow cellularity in myelodysplastic syndrome
}

\author{
Howard L Ribeiro Jr, ${ }^{1,2}$ Allan Rodrigo S Maia, ${ }^{1,2}$ Roberta Taiane G de Oliveira, ${ }^{1,2}$ \\ Marília Braga Costa, ${ }^{1,2}$ Izabelle Rocha Farias, ${ }^{1,2}$ Daniela de Paula Borges, ${ }^{1,2}$ \\ Juliana Cordeiro de Sousa, ${ }^{1,2}$ Silvia Maria M Magalhães, ${ }^{1,2}$ Ronald F Pinheiro ${ }^{1,2,3}$
}

${ }^{1}$ Cancer Cytogenomic

Laboratory, Center for Research and Drug Development (NPDM), Federal University of Ceara, Fortaleza, Ceara, Brazil ${ }^{2}$ Post-Graduate Program in Medical Science, Federal University of Ceara, Fortaleza, Ceara, Brazil

${ }^{3}$ Post-Graduate Program of Pathology, Federal University of Ceara, Fortaleza, Ceara, Brazil

Correspondence to Dr Ronald F Pinheiro, Federal University of Ceara, Center for Research and Drug Development (NPDM)

R. Coronel Nunes de Melo, 1000- $2^{\circ}$ andar-Rodolfo Teófilo-CEP, Fortaleza, Ceara 60430-275, Brazil; ronaldfpinheiro@uol.com.br

Received 2 December 2016 Revised 21 February 2017 Accepted 7 April 2017

To cite: Ribeiro $\mathrm{HL}$, Maia ARS, de Oliveira RTG, et al. I Clin Pathol Published Online First: [please include Day Month Year] doi:10.1136/jclinpath-2016204269

\section{ABSTRACT}

Objective To evaluate the expression of genes related to nuclear excision (ERCC8, XPA and XPC), homologous recombination and non-homologous end-joining (ATM, $B R C A 1, B R C A 2$ and LIG4) repair mechanisms, using quantitative PCR methodologies, and it relation with bone marrow cellularity in myelodysplastic syndrome (MDS).

Methods and results $A$ total of 51 adult de novo patients with MDS (3 refractory anaemia (RA), 11 refractory anaemia with ringed sideroblasts (RARS), 28 refractory cytopenia with multilineage dysplasia (RCMD), 3 refractory anaemia with excess blasts type I (RAEB-I), 5 refractory anaemia with excess blasts type II (RAEB-II), and 1 chronic myelomonocytic leukaemia (CMML) were evaluated. For karyotype, $16.2 \%$ patients were defined as very low prognosis, $59.5 \%$ low risk, $8.1 \%$ intermediate risk, $5.4 \%$ high risk and $10.8 \%$ very high risk. For bone marrow cellularity, $17.6 \%, 17.6 \%$ and $64.7 \%$ presented as hypocellular, normocellular and hypercellular, respectively. Patients with hypocellular MDS had significantly decreased expression of ATM $(p=0.000), B R C A 1(p=0.014), B R C A 2(p=0.003)$, LIG4 $(\mathrm{p}=0.004)$ and $E R C C 8(\mathrm{p}=0.000)$ than those with normocellular/hypercellular bone marrow, whereas XPA $(p=0.049)$ and $X P C(p=0.000)$ genes were increased. In patients with hypoplastic MDS, a low expression of ATM ( $\mathrm{p}=0.0268)$, LIG4 $(\mathrm{p}=0.0199)$ and ERCC8 $(p=0.0493)$ was significantly associated with the presence of chromosomal abnormalities. We detected positive correlations between $B R C A 1$ and $B R C A 2$ $(r=0.416 ; p=0.007)$, ATM and LIG4 ( $r=0.472$; $\mathrm{p}=0.001), L / G 4$ and BRCA1 $(\mathrm{r}=0.333 ; \mathrm{p}=0.026), \mathrm{L} / G 4$ and BRCA2 $(\mathrm{r}=0.334 ; \mathrm{p}=0.025)$, ATM and XPA $(\mathrm{r}=0.377 ; \mathrm{p}=0.008)$, ATM and $X P C(\mathrm{r}=0.287$; $p=0.046), L / G 4$ and $X P C(r=0.371 ; p=0.007)$ and $X P A$ and $X P C$ genes $(r=0.895 ; p=0.0000)$. We also found among all patients evaluated that correlation with LIG4 occurred most often.

Conclusions These correlations demonstrate the important intrinsic relations between single and double DNA strand breaks genes in MDS, emphasising that these genes are related to MDS pathogenesis.

\section{INTRODUCTION}

Myelodysplastic syndrome (MDS) is a heterogeneous group of clonal haematopoietic stem cell disorders characterised by peripheral cytopenias due to ineffective haematopoiesis. ${ }^{1-3}$ Bone marrow cellularity in patients with MDS is usually hypercellular or normocellular. ${ }^{4}$ According to $\mathrm{WHO}^{5}$
$10-15 \%$ of patients with MDS can present hypocellular bone marrow, which has prognostic significance for hypoplastic MDS (hMDS). ${ }^{5-8}$

Schemenau et $a l^{9}$ evaluated the prognostic importance of cellularity among 1270 patients with MDS and showed that for cases with hypercellular, normocellular and hypocellular bone marrow there was a significant difference in median survival of 25 months, 42 months and 38 months, respectively. ${ }^{9}$ Acute myeloid leukaemia progression rates were $33 \%$ after 2 years (hypercellular), whereas normocellular and hypocellular cases showed a progression of only $19 \%$. These results suggest that hypercellular bone marrow in MDS is related to a poor prognosis. ${ }^{9}$

Patients with hypocellular bone marrow are usually younger, have immune abnormalities such as vasculitis, pyoderma and respond to antithymocyte globulin (Atgam) treatment. ${ }^{10-12}$ In a study of the pathogenesis of hMDS, Young et al ${ }^{13}$ reported that $\mathrm{T}$ cells affect bone marrow destruction as in aplastic anaemia, reinforcing hMDS as a distinct entity with a different prognosis.

DNA repair is an important mechanism for maintaining the integrity of multicellular organisms and for ensuring genomic stability. ${ }^{14}$ DNA damage constantly arises from DNA replication, spontaneous chemical reactions and assaults by external or metabolism-derived agents. ${ }^{15}{ }^{16}$ At least four main, partially overlapping damage repair pathways operate in mammals: nucleotide-excision repair (NER), base excision repair (BER), homologous recombination (HR) and non-homologous endjoining (NHEJ). NER and BER are related to single-strand lesion and HR and NHEJ, to doublestrand breaks (DSBs). DSBs are mutagenic DNA lesions $^{3} 1417$ and are considered to exert important biological effects on the formation of chromosomal aberrations, cell death and transformation, ${ }^{3} 1417$ which are common features of MDS. NER eliminates helix-distorting DNA damage, a broad category of damage that affects one of the two DNA strands. ${ }^{15}$ Problems in NER are also related to cancer and senescence. ${ }^{15}$

We previously demonstrated that polymorphisms of DNA repair genes related to HR are associated with the pathogenesis of MDS. ${ }^{18}{ }^{19}$ We found that the polymorphisms of ATM, RAD51, XRCC5 and XRCC6 are associated with the genesis and aetiology of MDS. ${ }^{18}{ }^{19}$ Importantly, we recently showed that these polymorphisms are functional, influencing the level of expression of ATM, XRCC6 and LIG4. ${ }^{20}$ 


\section{Original article}

The aim of this study was to evaluate the relation between expression of genes related to NER (ERCC8, XPA and XPC), $\mathrm{HR}$ and NHEJ (ATM, BRCA1, BRCA2 and LIG4) repair mechanisms and bone marrow cellularity in MDS.

\section{PATIENTS AND METHODS}

\section{Patients}

Fifty-one adult de novo patients with MDS were diagnosed at Federal University of Ceara according to WHO. ${ }^{10}$ The patients were evaluated according to WHO classification ${ }^{10}$ and the International Prognosis Score System revised (IPSS-R). ${ }^{21}$

Bone marrow cellularity was assessed on biopsy specimens and was stratified as hypocellular, normocellular and hypercellular, in relation to the patient's age. Hypocellularity in patients with MDS was defined as $<30 \%$ in those aged $<70$ years, and $20 \%$ in patients $>70 \%$ years, according to the established criteria of the European consensus on grading bone marrow fibrosis and assessment of cellularity. ${ }^{22}$

The study was approved by the ethics committee of the Federal University of Ceara (No. 1.292.509) and conducted according to the Declaration of Helsinki. Informed consent was obtained from all participants included in this study.

\section{Cytogenetic analysis}

Conventional G-band karyotype analysis was performed on bone marrow cells of 51 de novo patients with MDS according to the protocol already established in our laboratory. ${ }^{23}$ Briefly, cultures were established in RPMI 1640 medium (Gibco, Grand Island, New York, USA) containing 30\% fetal calf serum. For the 24-hour culture, colcemid was added at a final concentration of $0.05 \mu \mathrm{g} / \mathrm{mL}$ for the final $30 \mathrm{~min}$. After harvesting, the cells were exposed to a hypotonic $\mathrm{KCl}$ solution $(0.068 \mathrm{~mol} / \mathrm{L})$ and fixed with Carnoy buffer (acetic acid/methanol in a 1:3 proportion). The slides were prepared and stained using Giemsa solution. A minimum of 20 metaphases was analysed whenever possible. The karyotype was prepared using a CytoVision Automated Karyotyping System (Applied Imaging, San Jose, California, USA) and described according to the International System for Human Cytogenetic Nomenclature (2013).

\section{Total RNA extraction}

Total RNA extractions from isolated mononuclear cells (bone marrow), obtained from patients with MDS, were performed with TRizol Reagent (Invitrogen, Carlsbad, California, USA), according to the manufacturer's protocol.

Table 1 Characteristics of patients with MDS according to bone marrow cellularity

\begin{tabular}{|c|c|c|c|}
\hline Variables & Hypocellular MDS $(n=9)$ & Normal/hypercellular MDS $(n=9 / n=33)$ & $\mathrm{p}$ Value \\
\hline Age (years), mean (range) & $43(22-58)$ & $67(41-88)$ & 0.000 \\
\hline \multicolumn{4}{|l|}{ Gender } \\
\hline Male & $4(44.4)$ & $20(47.6)$ & \multirow[t]{2}{*}{0.863} \\
\hline Female & $5(55.6)$ & $22(52.4)$ & \\
\hline Haemoglobin (g/dL), mean (range) & $8.87(6.2-13.1)$ & $8.46(4.9-12.9)$ & 0.620 \\
\hline ANC $\left(\times 10 \mathrm{~L}^{-1}\right)$, mean (range) & $527.11(217-1075)$ & $2185.55(144-7429)$ & 0.000 \\
\hline Platelets $\left(\mathrm{mm}^{3}\right)$, mean (range) & $827900(12100-300000)$ & $7857110(10500-676000)$ & 0.140 \\
\hline Ring sideroblasts (\%), mean (range) & $8(0-70)$ & $19(0-80)$ & 0.290 \\
\hline Blasts (\%), mean (range) & $2(0-11)$ & $3.12(0-37)$ & 0.634 \\
\hline \multicolumn{4}{|l|}{ Transfusional dependence } \\
\hline Dependence & $4(44.4)$ & $23(56.1)$ & \multirow[t]{2}{*}{0.525} \\
\hline Non-dependence & $5(55.6)$ & $18(43.9)$ & \\
\hline \multicolumn{4}{|l|}{ WHO classification } \\
\hline RA & $0(0.0)$ & $3(7.1)$ & \\
\hline RARS & $1(11.1)$ & $10(23.8)$ & \\
\hline RCMD & $7(77.8)$ & $21(50.0)$ & \\
\hline RAEB & $1(11.1)$ & $7(16.7)$ & \\
\hline CMML-1 & $0(0.0)$ & $1(2.4)$ & \\
\hline High-grade (RA, RARS, RCMD and CMML) & $8(88.9)$ & $35(83.3)$ & \\
\hline Low-grade (RAEB) & $1(11.1)$ & $7(16.7)$ & 0.173 \\
\hline \multicolumn{4}{|l|}{ Karyotype } \\
\hline Normal & $2(28.6)$ & $19(63.3)$ & \multirow[t]{3}{*}{0.095} \\
\hline Abnormal & $5(71.4)$ & $11(36.7)$ & \\
\hline No metaphase & $2(14.3)$ & $12(85.7)$ & \\
\hline \multicolumn{4}{|l|}{ Cytogenetics prognosis } \\
\hline Very low+low+intermediate & $6(85.7)$ & $29(96.7)$ & \multirow[t]{2}{*}{0.249} \\
\hline High+very high & $1(14.3)$ & $1(3.3)$ & \\
\hline \multicolumn{4}{|l|}{ IPSS-R score } \\
\hline Very low+low+intermediate & $5(71.4)$ & $26(86.7)$ & \multirow[t]{2}{*}{0.325} \\
\hline High+very high & $2(28.6)$ & $4(13.3)$ & \\
\hline AML transformation & $2(25.0)$ & $5(12.8)$ & 0.378 \\
\hline
\end{tabular}




\section{cDNA synthesis}

cDNA was generated from total RNA using the high-capacity cDNA reverse transcription kit (Applied Biosystems, San Jose, California, USA), according to the manufacturer's protocol. cDNA synthesis was generated using Mastercycler Pro Vapor Protect Technology machine (Eppendorf, Hamburg, Germany). cDNA samples were stored at $-20^{\circ} \mathrm{C}$.

\section{Quantitative real-time PCR}

Quantitative real-time PCR reactions were based on TaqMan methodology (Applied Biosystems, Carlsbad, California, USA) and run on a 7500 Fast System (Applied Biosystems, Carlsbad, California, USA). Predeveloped TaqMan gene expression assays for ATM (Hs01112344 m1), BRCA1 (Hs01556191 m1), BRCA2 (Hs01037423), LIG 4 (Hs00934061 m1), ERिCC8 (Hs01122124_m1), XPA (Hs00166045_m1) and XPC (Hs01104213_m1) as well as the TaqMan Universal Master Mix II, with uracil N-glycosylase (Applied Biosystems, Carlsbad, California, USA) were used to quantify mRNA expression. The expression level of the $\beta 2$-microglobulin gene $(B 2 M)$ and ubiquitin $(U B C)$ were used to normalise differences in input cDNA. Each sample was performed in duplicate and the expression ratios were calculated using the $2^{-\Delta C q}$ method. ${ }^{24}$

\section{Statistical analysis}

Data on relative mRNA expression $\left(\Delta C_{q}\right.$ values-quantitative cycle) were expressed as mean and range (maximum and minimum) in order to determine the possible association between relative gene expressions and the analysed variables. Normality was evaluated by Shapiro-Wilk test. Outliers were removed.

Student's t-test or one-way analysis of variance with Tukey/ Games-Howell post hoc test were used to analyse the associations between gene expression and the variables. The homogeneity of variances for all variables was tested by Levene's test. Multinomial logistic regression (MLR) analysis was used to estimate the ORs for each gene that might contribute to cellularity.

The best DNA repair expression cutoff point predicting MDS overall survival was calculated using the web-based Cutoff Finder software $^{9}$ (Cutoff Finder-http://molpath.charite.de/cutoff/index. jsp) by Kaplan-Meier curve analysis based on the log-rank test.

Pearson's correlation test was used to obtain $r$ and $r^{2}$ values. Statistical analyses were performed using the GraphPad Prism 5 (GraphPad Prism software, La Jolla, California, USA) and SPSS 20.0 (SPSS Inc, Chicago, Illinois, USA) computer software programs. Probability level ( $\mathrm{p}$ value) $<0.05$ was assumed.

\section{RESULTS}

Patients

Characteristics of the patients with MDS are shown in table 1. A total of 51 adult de novo patients with MDS (3 refractory anaemia (RA), 11 refractory anaemia with ringed sideroblasts (RARS), 28 refractory cytopenia with multilineage dysplasia (RCMD), 3 refractory anaemia with excess blasts type I (RAEBI), 5 refractory anaemia with excess blasts type II (RAEB-II), and 1 chronic myelomonocytic leukaemia (CMML) were analysed according to WHO classification. ${ }^{10}$ Cytogenetic analyses were performed in $37 / 51(72.5 \%)$ patients. Of those, $21(56.8 \%)$ showed normal karyotype, 16 (43.2\%) showed abnormal karyotype; $14(27.5 \%)$ presented no metaphases (table 1$)$. For karyotype, $6(16.2 \%)$ patients were defined as having a very low prognosis, $22(59.5 \%)$ as low risk, $3(8.1 \%)$ as intermediate risk, $2(5.4 \%)$ as high risk and $4(10.8 \%)$ as very high risk, according to IPSS- $\mathrm{R}^{21}$ (table 1 ).

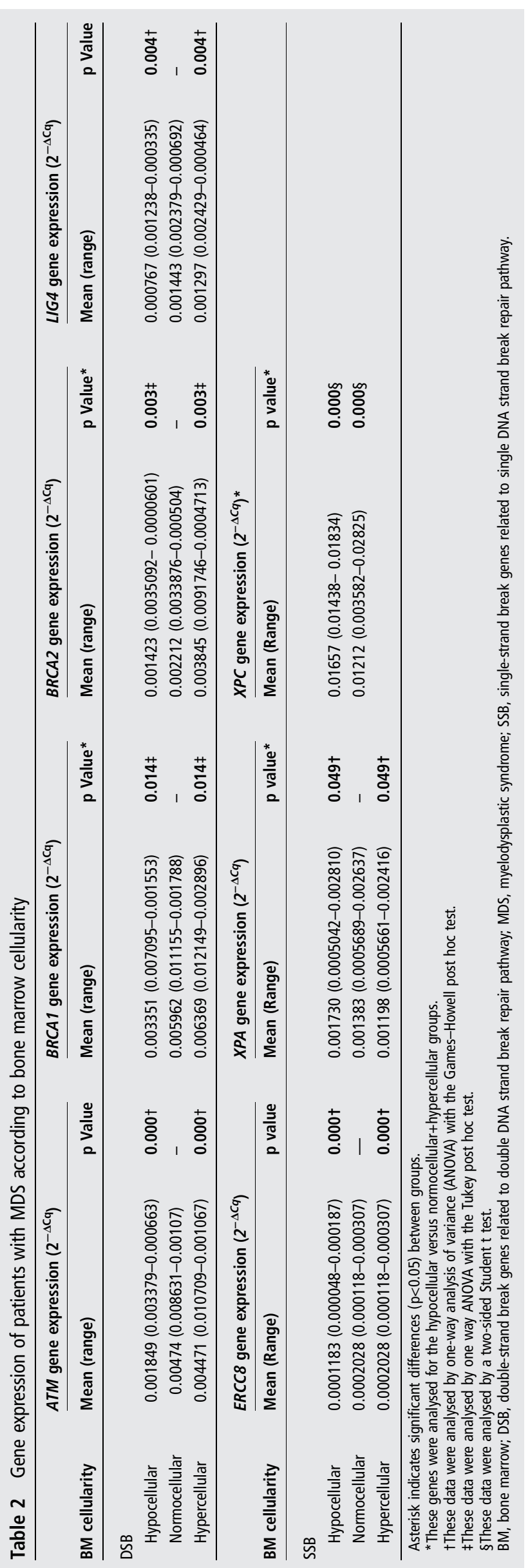




\section{Original article}

For bone marrow cellularity, $9(17.6 \%)$ patients presented hypocellular bone marrow, 9 (17.6\%) normocellular and 33 (64.7\%) hypercellular (table 1). For patients with hypocellular MDS, 5/7 (71.4\%) had chromosomal abnormalities (table 1), whereas for patients with normocellular/hypercellular hMDS $11 / 30(36.7 \%)$ were found to have abnormalities (table 1). We determined that hMDS was associated with a lower count of neutrophils $(p=0.000)$ and younger patients $(p=0.000)$ (table 1).

\section{mRNA expression of DNA repair genes in relation to bone marrow cellularity}

We evaluated mRNA expression of ATM, BRCA1, BRCA2, LIG4, ERCC8, XPA and XPC genes related to the bone marrow cellularity analysis. The mRNA expressions of patients with MDS are shown in table 2 .

Patients with hypocellular MDS presented significantly lower ATM ( $\mathrm{p}=0.000 ; 95 \% \mathrm{CI}=0.001330$ to 0.003914$)$ mRNA expression levels than patients with hypercellular bone marrow (figure 1A). We also detected an important decrease of BRCA1 expression ( $\mathrm{p}=0.014 ; 95 \%$ CI 0.000514 to 0.005521$), B R C A 2$ $(\mathrm{p}=0.003 ; 95 \%$ CI 0.000709 to 0.004136$)$, LIG4 $(\mathrm{p}=0.004$; 95\% CI 0.000162 to 0.000899$)$ and ERCC8 ( $\mathrm{p}=0.000 ; 95 \%$ CI 0.000070 to 0.000245 ) genes (figure $1 \mathrm{~B}-\mathrm{E}$ ) in hMDS.

On the other hand, we found that there is an increase of XPA $(\mathrm{p}=0.049 ; 95 \%$ CI 0.000000182 to 0.001064$)$ and $X P C$ $(\mathrm{p}=0.000 ; 95 \%$ CI 0.002192 to 0.006704$)$ expression in hMDS (figure $1 \mathrm{~F}, \mathrm{G}$ ).
Analysis of karyotype in patients with hypoplastic MDS in relation to DNA repair genes

Patients with hMDS who showed low expression of ATM $(\mathrm{p}=0.0268 ; 95 \%$ CI 0.005891 to 0.0006105$), \quad$ LIG4 $(\mathrm{p}=0.0199 ; 95 \%$ CI 0.001239 to 0.0001663$)$ and ERCC8 $(\mathrm{p}=0.0493 ; 95 \% \mathrm{CI}=0.000303$ to 0.0000007$)$ genes were significantly associated with the presence of chromosomal abnormalities (see figure 2A-C).

Low expression was considered when the mean of values of ATM, LIG4 and ERCC8 gene expressions were significantly lower than the mean observed for patients with hMDS with or without presence of chromosomal abnormalities (table 3).

\section{Overall survival by Cutoff Finder of DNA repair genes in patients with MDS}

We determined the cutoff value using the Cutoff Finder biostatistical tool to discriminate survival by Kaplan-Meier with log-rank post-test ${ }^{9}$ (table 4). This method correlates the dichotomised biomarker with a binary outcome using logistic regression. ${ }^{9}$

First, we selected 0.001638 as the optimal cutoff value for all subsequent analyses to differentiate between lower LIG4 $(<0.001638)$ and higher LIG4 $(>0.001638)$ gene expression (figure 3A). Overall, 36 (70.6\%) patients with MDS were considered to be lower LIG4 and 15 (29.4\%) considered higher LIG4 (figure 3A, B). Lower LIG4 patients with MDS were associated with a higher overall survival $(\mathrm{p}=0.017 ; \mathrm{HR}=2.42 ; 95 \%$ CI 1.14 to 5.13 ) (figure 3C).
A
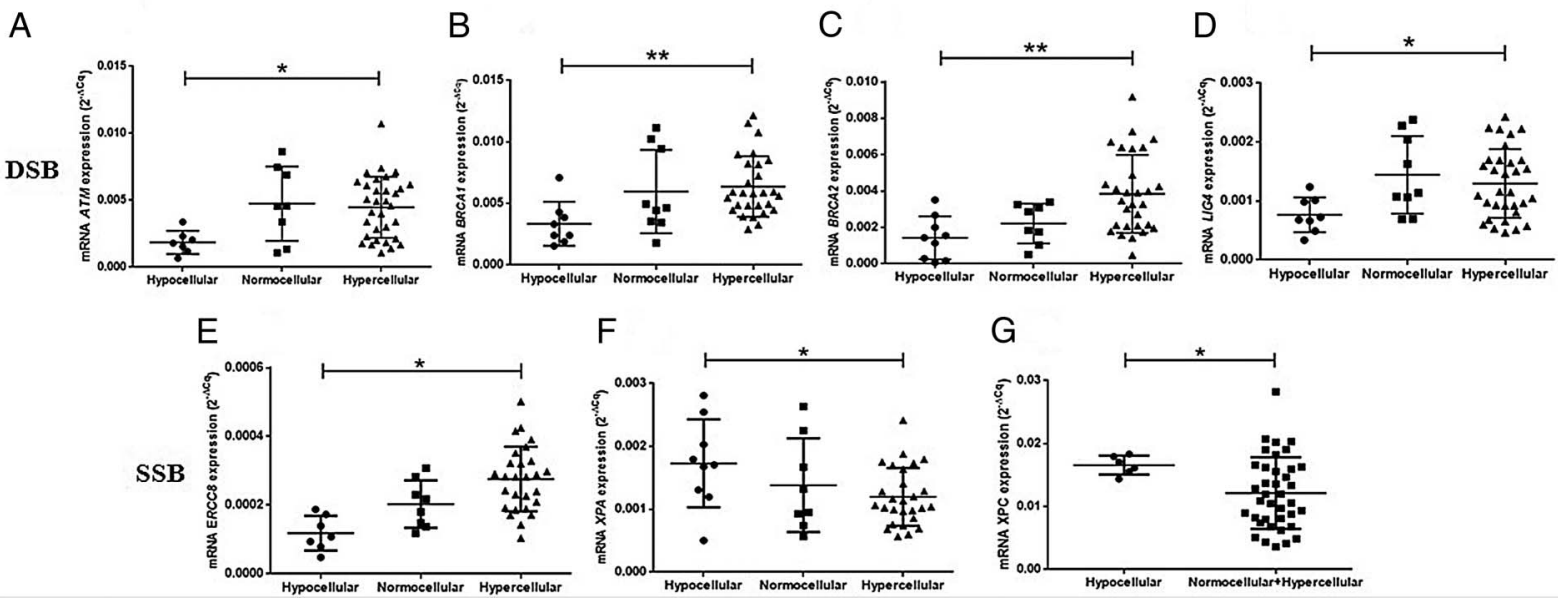

Figure 1 DNA repair genes analysis according to bone marrow cellularity. (A) mRNA ATM expression. (B) mRNA BRCA1 expression. (C) mRNA $B R C A 2$ expression. (D) mRNA LIG4 expression. (E) mRNA ERCC8 expression. (F) mRNA XPA expression. (G) mRNA XPC expression. Asterisk indicates significant differences $(p<0.05)$ between groups by one-way analysis of variance test. DSB, double-strand break genes related to double DNA strand break repair pathway; SSB, single-strand break genes related to single DNA strand break repair pathway.
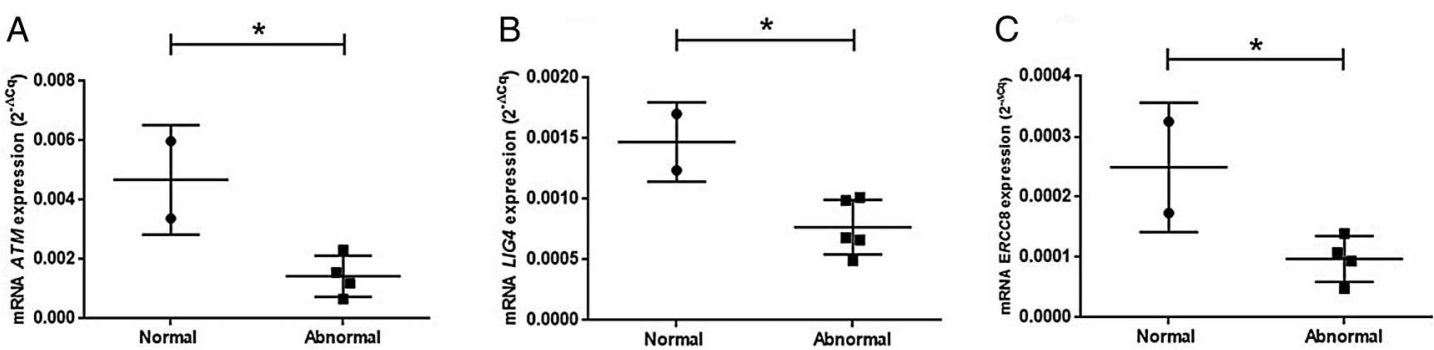

Figure 2 Plots of ATM, LIG4 and ERCC8 gene amplification analysis compared with the presence of chromosomal abnormalities in patients with hypocellular myelodysplastic syndrome. Asterisk indicates significant differences $(p<0.05)$. 
Table 3 Comparison of DNA repair gene expression according to presence of chromosomal abnormalities in subgroups of bone marrow cellularity

\begin{tabular}{|c|c|c|c|c|c|c|c|c|}
\hline \multirow[b]{2}{*}{ BM cellularity } & \multicolumn{2}{|l|}{ ATM gene expression $\left(2^{-\Delta C q}\right)$} & \multicolumn{2}{|l|}{$B R C A 1$ gene expression $\left(2^{-\Delta C q}\right)$} & \multicolumn{2}{|l|}{$B R C A 2$ gene expression $\left(2^{-\Delta C q}\right)$} & \multicolumn{2}{|l|}{ LIG4 gene expression $\left(2^{-\Delta C q}\right)$} \\
\hline & Mean (range) & $p$ Value & Mean (range) & p Value & Mean (range) & $p$ Value & Mean (range) & p Value \\
\hline \multicolumn{9}{|l|}{$D S B$} \\
\hline \multicolumn{9}{|l|}{ Hypocellular } \\
\hline Normal & $0.004681(0.003379-0.005983)$ & $0.026^{*}$ & $0.00335(0.002408-0.004292)$ & 0.583 & $0.0017(0.001551-0.002004)$ & 0.442 & $0.00147(0.001238-0.001702)$ & 0.019 * \\
\hline Abnormal & $0.001430(0.000663-0.002309)$ & & $0.00278(0.001553-0.003859)$ & & $0.0011(0.000160-0.002669)$ & & $0.00076(0.000492-0.001014)$ & \\
\hline \multicolumn{9}{|l|}{ Normocellular } \\
\hline Normal & $0.006017(0.004554-0.007479)$ & 0.324 & $0.00387(0.003453-0.00464)$ & 0.543 & $0.0026(0.001743-0.003388)$ & 0.803 & $0.00138(0.000697-0.002379)$ & 0.969 \\
\hline Abnormal & $0.003973(0.003383-0.004563)$ & & $0.00312(0.001788-0.004451)$ & & $0.0024(0.001836-0.003073)$ & & $0.00135(0.001074-0.001628)$ & \\
\hline \multicolumn{9}{|l|}{ Hypercellular } \\
\hline Normal & $0.005026(0.001408-0.01071)$ & 0.775 & $0.00680(0.003871-0.01215)$ & 0.546 & $0.0043(0.001413-0.009175)$ & 0.177 & $0.00135(0.000464-0.002429)$ & 0.864 \\
\hline \multirow[t]{2}{*}{ Abnormal } & $0.004750(0.00167-0.007398)$ & & $0.00611(0.004197-0.008506)$ & & $0.0031(0.001572-0.006852)$ & & $0.00131(0.000512-0.002215)$ & \\
\hline & ERCC8 gene expression $\left(2^{-\triangle C q}\right)$ & & $X P A$ gene expression $\left(2^{-\Delta C q}\right)$ & & $X P C$ gene expression $\left(2^{-\Delta C q}\right)$ & & & \\
\hline BM cellularity & Mean (Range) & p Value & Mean (Range) & p Value & Mean (Range) & $\mathrm{p}$ Value & & \\
\hline
\end{tabular}

SSB

Hypocellular Normal

$0.00024(0.0001733-0.000324)$

0.049 *

$0.00085(0.000504-0.001196)$ $0.00190(0.001308-0.002810)$

0.070

$0.00979(0.005201-0.01438)$

0.242

Normocellular $0.000097(0.000048-0.000139)$

$0.01829(0.01089-0.03180)$

0.942

Normal

$0.000422(0.000230-0.000731)$

0.418

$0.00137(0.000568-0.002637)$

0.564

$0.00755(0.00411-0.01369)$ $0.00787(0.00679-0.00895)$

Hypercellular

Normal

$0.000396(0.000103-0.000501)$

0.234

$0.00025(0.000191-0.00036)$

0.471

$0.01631(0.00434-0.05181)$

0.336

Asterisk in bold text indicates significant differences $(p<0.05)$ between groups analysed by Student's $t$-test two sided

$0.01221(0.00622-0.02023)$

BMC, bone marrow cellularity; DSB, double-strand break genes related to double DNA strand break repair pathway; SSB, single-strand break genes related to single DNA strand break repair pathway. 


\section{Original article}

Table 4 Multinominal logistic regression for the DNA repair gene expressions concerning bone marrow cellularity of patients with MDS

\begin{tabular}{|c|c|c|c|c|c|c|c|c|}
\hline \multirow[b]{2}{*}{ Gene } & \multirow[b]{2}{*}{ BMC } & \multirow[b]{2}{*}{ Cases (n) } & \multirow[b]{2}{*}{ Cut-off point* } & \multirow[b]{2}{*}{$\chi^{2}$} & \multicolumn{4}{|c|}{ Multinominal logistic regressiont } \\
\hline & & & & & Wald & $\mathrm{p}$ Value & OR & $95 \% \mathrm{Cl}$ \\
\hline ATM expression & & & 0.001821 & 0.052 & & & & \\
\hline \multirow[t]{3}{*}{ Lowerł } & Hypocellular & $4(36.4)$ & & & - & - & - & - \\
\hline & Normocellular & $2(18.2)$ & & & - & - & - & - \\
\hline & Hypercellular & $5(45.4)$ & & & - & - & - & - \\
\hline \multirow[t]{3}{*}{ Higher§ } & Hypocellular & $3(8.3)$ & & & - & - & - & - \\
\hline & Normocellular & $6(16.7)$ & & & - & - & - & - \\
\hline & Hypercellular & $27(75.0)$ & & & - & - & - & - \\
\hline$B R C A 1$ expression & & & 0.0105 & 0.817 & & & & \\
\hline \multirow[t]{3}{*}{ Lowerł } & Hypocellular & $8(19.5)$ & & & - & - & - & - \\
\hline & Normocellular & $8(19.5)$ & & & - & - & - & - \\
\hline & Hypercellular & $25(61.0)$ & & & - & - & - & - \\
\hline \multirow[t]{3}{*}{ Higher§ } & Hypocellular & $0(0.0)$ & & & - & - & - & - \\
\hline & Normocellular & $1(25.0)$ & & & - & - & - & - \\
\hline & Hyercellular & $3(75.0)$ & & & - & - & - & - \\
\hline$B R C A 2$ expression & & & 0.001741 & 0.007 & & & & \\
\hline \multirow[t]{3}{*}{ Lowerł } & Hypocellular & $6(50.0)$ & & & 8.075 & 0.004 & 12.500 & 2.190 to 71.363 \\
\hline & Normocellular & $2(16.7)$ & & & 0.563 & 0.453 & 2.083 & 0.306 to 14.168 \\
\hline & Hypercellular & $4(33.3)$ & & & - & - & - & - \\
\hline \multirow[t]{3}{*}{ Higher§ } & Hypocellular & $3(8.8)$ & & & 8.075 & 0.004 & 0.080 & 0.014 to 0.457 \\
\hline & Normocellular & $6(17.7)$ & & & 0.563 & 0.453 & 0.480 & 0.071 to 3.264 \\
\hline & Hypercellular & $25(73.5)$ & & & - & - & - & - \\
\hline LIG4 expression & & & 0.001638 & 0.196 & & & & \\
\hline \multirow[t]{3}{*}{ Lowerł } & Hypocellular & $8(22.2)$ & & & - & - & - & - \\
\hline & Normocellular & $6(16.7)$ & & & - & - & - & - \\
\hline & Hypercellular & $22(61.1)$ & & & - & - & - & - \\
\hline \multirow[t]{3}{*}{ Higher§ } & Hypocellular & $0(0.0)$ & & & - & - & - & - \\
\hline & Normocellular & $3(23.1)$ & & & - & - & - & - \\
\hline & Hypercellular & $10(76.9)$ & & & - & - & - & - \\
\hline$E R C C 8$ expression & & & 0.0002351 & 0.019 & & & & \\
\hline \multirow[t]{3}{*}{ Lower‡ } & Hypocellular & $7(30.4)$ & & & 4.712 & 0.030 & 11.900 & 1.272 to 111.351 \\
\hline & Normocellular & $6(26.1)$ & & & 3.216 & 0.073 & 5.100 & 0.859 to 30.265 \\
\hline & Hypercellular & $10(43.5)$ & & & - & - & - & - \\
\hline \multirow[t]{3}{*}{ Higher§ } & Hypocellular & $1(5.0)$ & & & 4.712 & 0.030 & 0.084 & 0.009 to 0.786 \\
\hline & Normocellular & $2(10.0)$ & & & 3.216 & 0.073 & 0.196 & 0.033 to 1.164 \\
\hline & Hypercellular & $17(85.0)$ & & & - & - & - & - \\
\hline XPA expression & & & 0.001674 & 0.172 & & & & \\
\hline \multirow[t]{3}{*}{ Lower‡ } & Hypocellular & $3(9.7)$ & & & - & - & - & - \\
\hline & Normocellular & 7 (22.6) & & & - & - & - & - \\
\hline & Hypercellular & $21(67.7)$ & & & - & - & - & - \\
\hline \multirow[t]{3}{*}{ Higher§ } & Hypocellular & $6(30.0)$ & & & - & - & - & - \\
\hline & Normocellular & $9(17.6)$ & & & - & - & - & - \\
\hline & Hypercellular & $12(60.0)$ & & & - & - & - & - \\
\hline$X P C$ expression & & & 0.009534 & 0.345 & & & & \\
\hline \multirow[t]{3}{*}{ Lowerł } & Hypocellular & $1(6.2)$ & & & - & - & - & - \\
\hline & Normocellular & $4(25.0)$ & & & - & - & - & - \\
\hline & Hypercellular & $11(68.8)$ & & & - & - & - & - \\
\hline Higher§ & Hypocellular & $8(22.9)$ & & & - & - & - & - \\
\hline & Normocellular & $5(14.3)$ & & & - & - & - & - \\
\hline & Hypercellular & $22(62.9)$ & & & - & - & - & - \\
\hline
\end{tabular}

Bold text indicates significant differences $(p<0.05)$ between groups analysed by one-way analysis of variance.

${ }^{*}$ Cut-off points established by the Cutoff Finder web tool.

tMultinominal logistic regression analysis with significant differences in $\mathrm{p}<0.05$.

$\ddagger$ Patients were included when the gene expression was lower than or equal to the cutoff point according to Cutoff Finder software. The reference category is higher for MLR analysis.

$\S$ Patients were included when the gene expression was higher than the cutoff point according to Cutoff Finder software. The reference category is lower for MLR analysis.

$\chi^{2}$, Pearson's $\chi^{2} ; B M C$, bone marrow cellularity; MDS, myelodysplastic syndrome; MLR, multinomial logistic regression.

Based on 0.001674 cutoff point value for XPA gene analysis, we found that there were $21(41.2 \%)$ patients with a higher XPA and $30(58.8 \%)$ patients with a lower XPA (figure 3A, B). We observed that higher XPA (>0.001674) patients with MDS were associated with a lower overall survival $(\mathrm{p}=0.019 ; \mathrm{HR}=3.23$; 95\% CI 1.15 to 9.06 ) (figure 3E, F).

No difference in overall survival was detected for other genes related to HR (ATM, BRCA1, BRCA2) and NER (ERCC8 and 
A

cutoll $-0.001638 .15(29.4 \%)$ LIG6+. $36(70.6 \%)$ LIG.

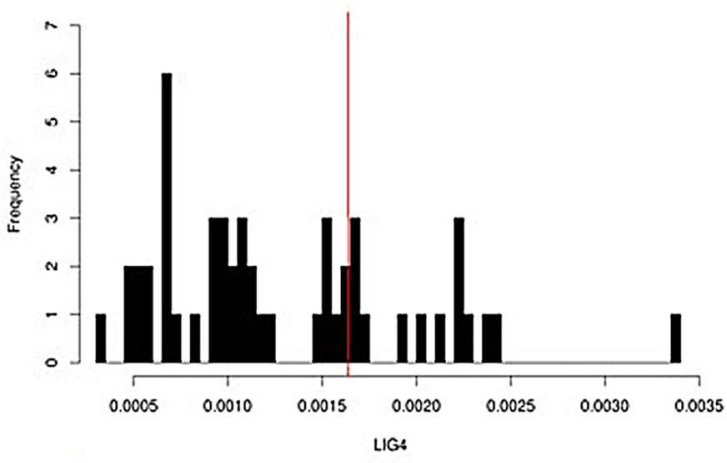

B

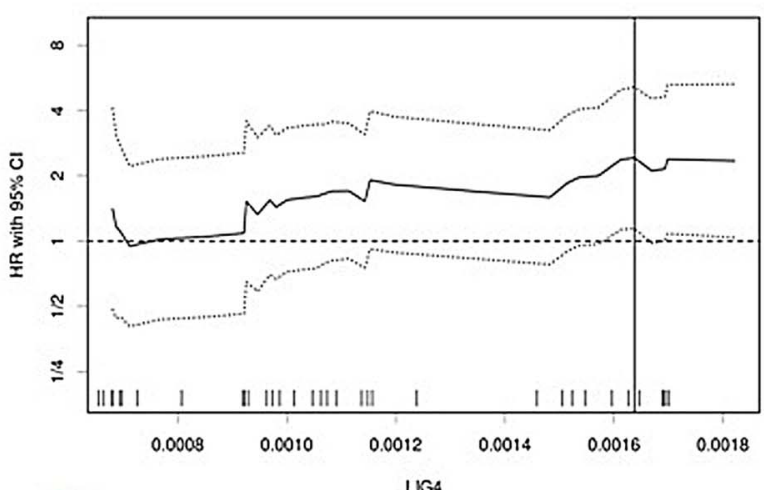

LIG4

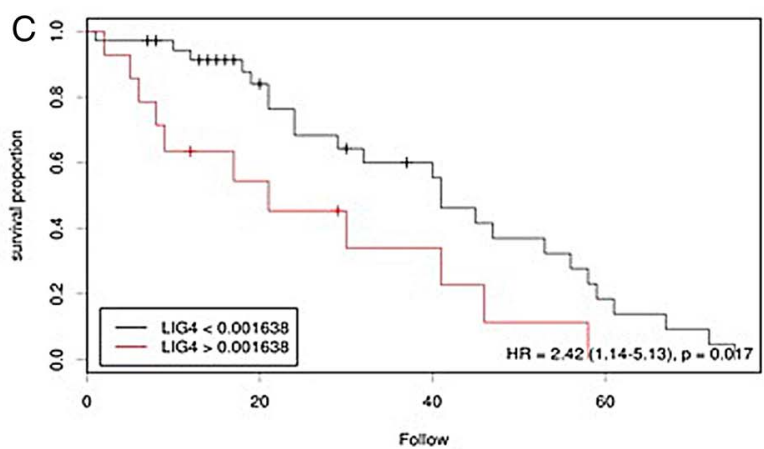

D cutolf $=0.001674,21(41.2 \%) \times P A+, 30(58.8 \%) \times P A$.

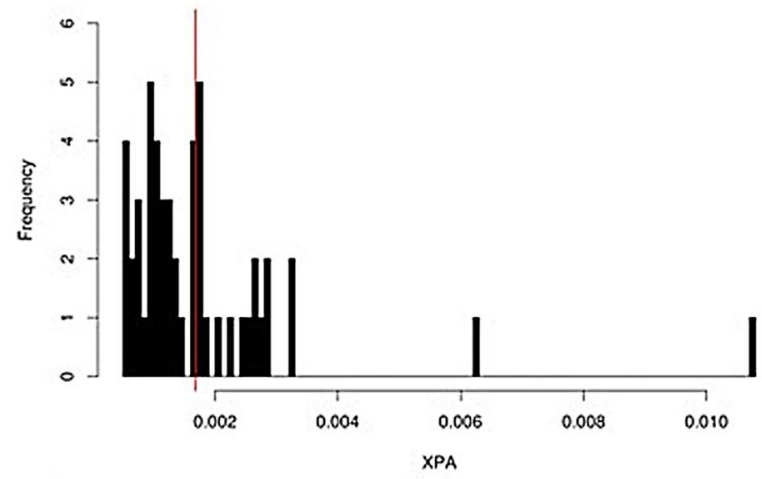

E

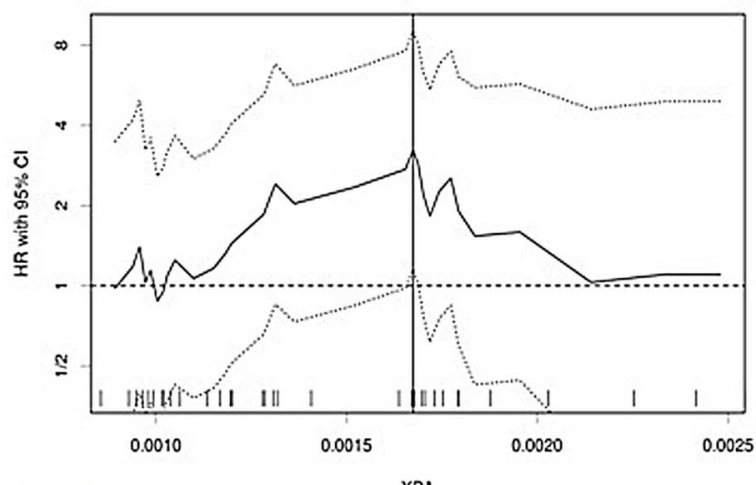

XPA

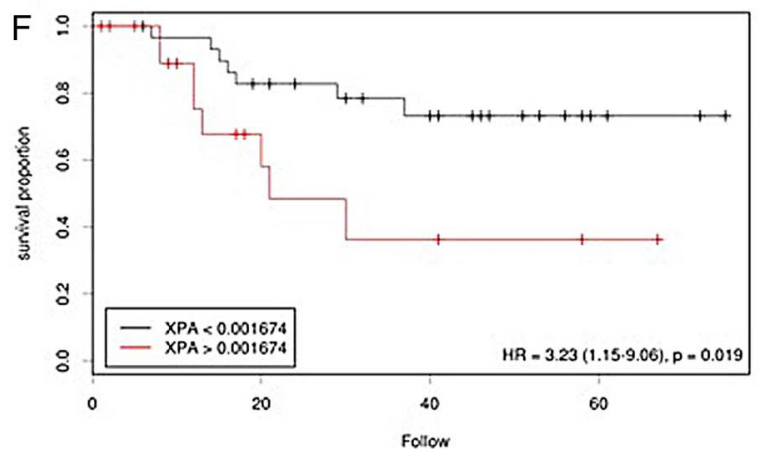

Figure 3 Analysis of cutoff points for LIG4 and XPA genes as predictive marker for higher survival of patients with myelodysplastic syndrome. Red lines mark the optimal cutoff point for LIG4 gene expression. (A, D) Histogram of $L I G 4$ and XPA gene expressions in 51 patients with myelodysplastic syndrome (MDS). ( $B, E)$ HR for disease-free survival depending on the cutoff point. $(C, F)$. HR for overall survival depending on the cutoff point.

The plots were generated using the biostatistical tool Cutoff Finder software.

$\mathrm{XPC}$ ) when their values were dichotomised as biomarkers with a binary outcome using logistic regression (data not presented).

\section{MLR analysis of expressions of DNA repair genes}

The expression of genes related to DSBs (ATM, BRCA1, BRCA2, LIG4) and single-strand breaks (SSBs) (ERCC8, XPA, XPC) was divided into two groups: low and high expression, according to cutoff point established by Cutoff Finder biostatistical web application. ${ }^{9}$

We identified two subgroups of patients according to gene expression: lower group (when expression was lower than or equal to the cutoff value) and higher group (when expression was higher than the cutoff value). ${ }^{9}$ We detected that the decreased expression of BRCA2 ( $\mathrm{p}=0.004, \mathrm{OR}=12.500,95 \%$ CI 2.190 to 71.363$)$ and ERCC $8(\mathrm{p}=0.030, \mathrm{OR}=11.900,95 \%$ CI 1.272 to 111.3512 ) genes were associated with diagnosis of hMDS (table 4).
No significant associations were found between the ATM, BRCA1, LIG4, XPA and XPC expressions and the bone marrow cellularity by MLR analysis ( $\mathrm{p}>0.05)$ (table 3$)$.

\section{Correlations of the mRNA expressions of DNA repair genes} in patients with MDS

By Pearson's correlation analysis, we observed significant correlations between the DSB (ATM, BRCA1, BRCA2, LIG4) and SSB (ERCC8, XPA and XPC) genes in MDS, demonstrating that these genes work in a dependent manner as a cascade of events (table 5).

We observed positive correlations between BRCA1 and BRCA2 $\left(\mathrm{r}=0.416 ; \mathrm{r}^{2}=0.173 ; \mathrm{p}=0.007\right)$ (figure $\left.4 \mathrm{~A}\right), A T M$ and LIG4 $\left(\mathrm{r}=0.472 ; \mathrm{r}^{2}=0.222 ; \mathrm{p}=0.001\right) \quad$ (figure 4B); LIG4 and BRCA1 $\left(\mathrm{r}=0.333 ; \mathrm{r}^{2}=0.110 ; \mathrm{p}=0.026\right)$ (figure 4C), LIG4 and BRCA2 ( $\left.\mathrm{r}=0.334 ; \mathrm{r}^{2}=0.111 ; \mathrm{p}=0.025\right) \quad$ (figure 4D), ATM and XPA ( $\left.\mathrm{r}=0.377 ; \mathrm{r}^{2}=0.142 ; \mathrm{p}=0.008\right)$ (figure 4E), ATM and 
Table 5 Pearson's correlation analysis of DNA repair genes in patients with MDS

\begin{tabular}{|c|c|c|c|c|c|c|c|}
\hline Pearson's correlation analysis & ATM & BRCA1 & BRCA2 & LIG4 & ERCC8 & $X P A$ & $X P C$ \\
\hline \multicolumn{8}{|l|}{ ATM } \\
\hline Pearson correlation ( $r$ ) & 1 & 0.255 & 0.232 & 0.472 & 0.267 & 0.377 & 0.287 \\
\hline$r^{2}$ & - & 0.065 & 0.053 & 0.222 & 0.071 & 0.142 & 0.082 \\
\hline p Value (2-tailed) & - & 0.099 & 0.135 & 0.001 & 0.088 & 0.008 & 0.046 \\
\hline $\mathrm{N}$ & 49 & 43 & 43 & 49 & 42 & 49 & 49 \\
\hline \multicolumn{8}{|l|}{$B R C A 1$} \\
\hline Pearson correlation (r) & 0.255 & 1 & 0.416 & 0.333 & 0.303 & 0.153 & 0.257 \\
\hline$r^{2}$ & 0.065 & - & 0.173 & 0.110 & 0.091 & 0.023 & 0.066 \\
\hline p Value (2-tailed) & 0.099 & - & 0.007 & 0.026 & 0.061 & 0.315 & 0.088 \\
\hline $\mathrm{N}$ & 43 & 45 & 41 & 45 & 39 & 45 & 45 \\
\hline \multicolumn{8}{|l|}{$B R C A 2$} \\
\hline Pearson correlation $(r)$ & 0.232 & 0.416 & 1 & 0.334 & 0.272 & -0.195 & 0.003 \\
\hline$r^{2}$ & 0.053 & 0.173 & - & 0.111 & 0.073 & 0.038 & 0.000009 \\
\hline p Value (2-tailed) & 0.135 & 0.007 & - & 0.025 & 0.090 & 0.199 & 0.987 \\
\hline $\mathrm{N}$ & 43 & 41 & 45 & 45 & 40 & 45 & 45 \\
\hline \multicolumn{8}{|l|}{ LIG4 } \\
\hline Pearson correlation (r) & 0.472 & 0.333 & 0.334 & 1 & 0.243 & 0.219 & 0.371 \\
\hline$r^{2}$ & 0.222 & 0.110 & 0.111 & - & 0.059 & 0.047 & 0.137 \\
\hline p Value (2-tailed) & 0.001 & 0.026 & 0.025 & - & 0.116 & 0.123 & 0.007 \\
\hline $\mathrm{N}$ & 49 & 45 & 45 & 51 & 43 & 51 & 51 \\
\hline \multicolumn{8}{|l|}{ ERCC8 } \\
\hline Pearson correlation (r) & 0.267 & 0.303 & 0.272 & 0.243 & 1 & -0.173 & -0.173 \\
\hline$r^{2}$ & 0.071 & 0.091 & 0.073 & 0.059 & - & 0.0299 & 0.0299 \\
\hline p Value (2-tailed) & 0.088 & 0.061 & 0.090 & 0.116 & - & 0.267 & 0.275 \\
\hline $\mathrm{N}$ & 42 & 39 & 40 & 43 & 43 & 43 & 43 \\
\hline \multicolumn{8}{|l|}{$X P A$} \\
\hline Pearson correlation ( $r$ ) & 0.377 & 0.153 & -0.195 & 0.219 & -0.173 & 1 & 0.895 \\
\hline$r^{2}$ & 0.142 & 0.023 & 0.038 & 0.047 & 0.0299 & - & 0.801 \\
\hline p Value (2-tailed) & 0.008 & 0.315 & 0.199 & 0.123 & 0.267 & - & 0.0000 \\
\hline $\mathrm{N}$ & 49 & 45 & 45 & 51 & 43 & 51 & 51 \\
\hline \multicolumn{8}{|l|}{$X P C$} \\
\hline Pearson correlation $(r)$ & 0.287 & 0.257 & 0.003 & 0.371 & -0.173 & 0.895 & 1 \\
\hline$r^{2}$ & 0.082 & 0.066 & 0.000009 & 0.137 & 0.0299 & 0.801 & - \\
\hline p Value (2-tailed) & 0.046 & 0.088 & 0.987 & 0.007 & 0.275 & 0.0000 & - \\
\hline $\mathrm{N}$ & 49 & 45 & 45 & 51 & 43 & 51 & 51 \\
\hline
\end{tabular}

Bold text indicates significant differences $(p<0.05)$ between groups analysed by Pearson's correlation test.

MDS, myelodysplastic syndrome.

XPC $\left(\mathrm{r}=0.287 ; \mathrm{r}^{2}=0.082 ; \mathrm{p}=0.046\right)($ figure $4 \mathrm{~F})$, LIG4 and XPC $\left(\mathrm{r}=0.371 ; \mathrm{r}^{2}=0.137 ; \mathrm{p}=0.007\right)$ (figure $\left.4 \mathrm{G}\right)$ and $X P A$ and $X P C$ genes $\left(r=0.895 ; r^{2}=0.801 ; p=0.0000\right)$ (figure $\left.4 \mathrm{H}\right)$.

\section{DISCUSSION}

We evaluated genes related to double and single DNA strand breaks in patients with MDS and detected that these genes are positively correlated and work in a dependent manner as a cascade of events and may be related to pathogenesis and prognosis of MDS. We found that genes recruited and activated by DNA double (ATM) and single (ERCC8) strand breaks are downregulated in hMDS. Ataxia telangiectasia mutated (ATM) is a serine/threonine protein kinase that, once activated, phosphorylates several key proteins that initiate activation of the DNA damage checkpoint, leading to cell cycle arrest, DNA repair or apoptosis. $^{19} 25$ ERCC8 (CSA), together with ERCC6 (CSB), is the cell signalling that begins the transcription-coupled repair subpathway of NER. ${ }^{26}$ As both genes act as primary sensors of DNA lesions, we suggest that DNA repair is deficient in hMDS and DNA damage tends to accumulate.
Importantly, we also found that for patients with hMDS with low expression of ATM and ERCC8 there was a significant association with the presence of chromosomal abnormalities, reinforcing the intrinsic link between single- and double-strand breaks in MDS, principally in hypoplastic MDS. SSBs are not usually associated with a major DNA lesion and, ${ }^{19}$ consequently, chromosomal breaks, but may be the first step to a DSB if not properly corrected. ${ }^{27}$ The estimated numbers of SSBs and spontaneous base losses in nuclear DNA are as high as $10^{4}$ per cell per day. ${ }^{19}$ If the cell signalling of this type of lesion shows low expression, it may help to increase the chance of DSBs and consequent chromosomal abnormalities, as presented here.

Among several protein complexes involved in HR repair pathways, BRCA1/2, which are members of the BRCA family, were initially identified as biomarkers of breast cancer. ${ }^{28-30}$ BRCA1/2 work with proteins of the RAD complex to control of genomic stability. $^{28-30}$ To the best of our knowledge, this is the first report to demonstrate that both genes show low expression in hMDS and are intrinsically and positively correlated, reinforcing the suggestion that $B R C A 1 / 2$ work in a similar way. This result 
A

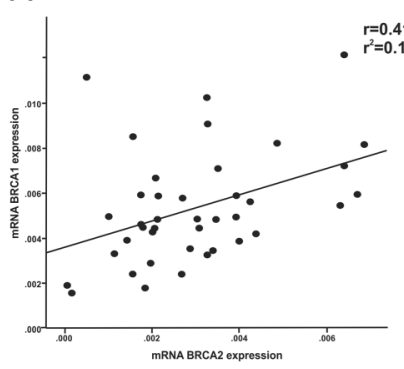

E

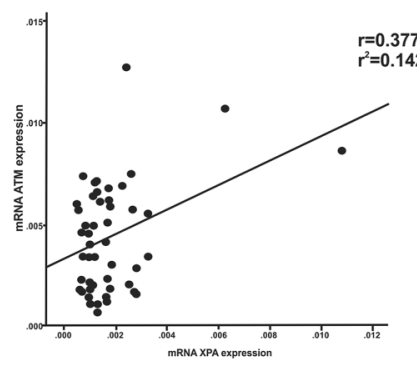

B

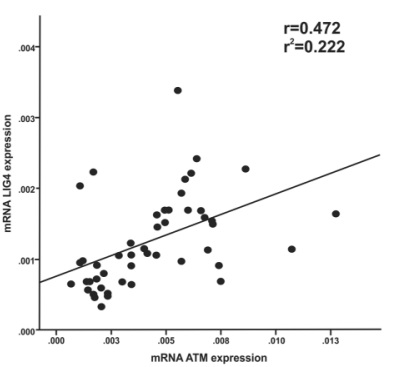

F

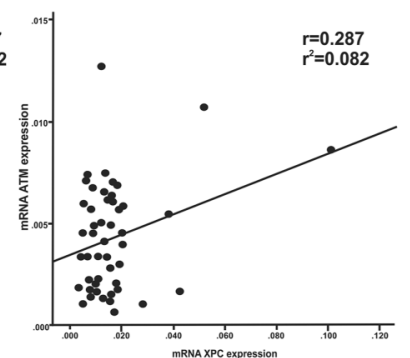

C

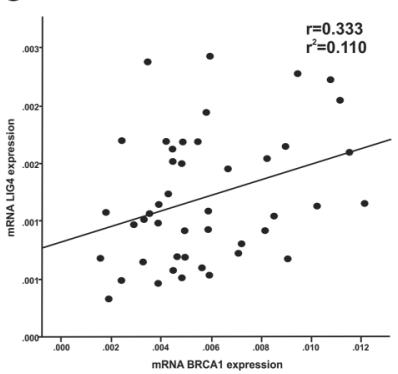

G

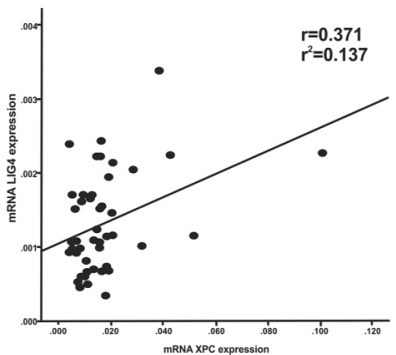

D

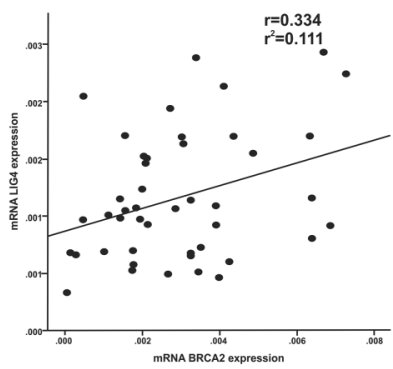

$\mathrm{H}$

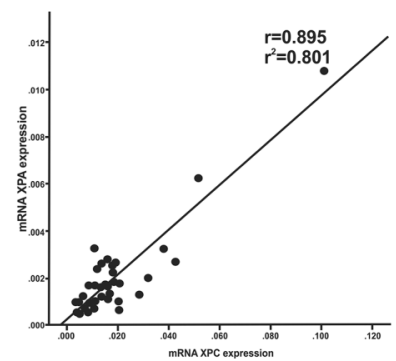

Figure 4 Plots of Pearson's correlation analysis of DNA repair gene expressions of patients with myelodysplastic syndrome.

also corroborates the importance of both genes in maintaining genomic stability because their low expression among patients reported here was associated with an increase of chromosomal abnormalities.

The low expressions of BRCA1 and BRCA2 genes have also been reported in solid tumours, such as epithelial ovarian carcinoma, prostate cancer and breast cancer. ${ }^{31} 32$ Using MLR analysis, we detected that decreased expression of BRCA2 was associated with an increased chance of developing hMDS with an OR of 12 . We were initially surprised with this result because $B R C A 2$ is associated with DNA repair, but Jeong et $a l^{33}$ showed that BRCA2 deficiency leads to $T$ cell loss and immune dysfunction. In a very elegant murine model, the researchers demonstrated that mice with deficiency of BRCA2 show reduction in splenic $\mathrm{T}$ cell number and less interferon $\gamma$ and interleukin 4, suggesting a functional defect of BRCA2-deficient $\mathrm{T}$ cells. ${ }^{33}$ $B R C A 2$ deficiency mice showed a greatly reduced production of IgM (ninefold reduction) compared with IgG1 (threefold reduction) or IgG2a (less than threefold reduction) isotypes. ${ }^{32}$ All these results suggest that $B R C A 2$ is also linked to immune abnormalities. $^{32}$ As hMDS is considered an immune disorder, ${ }^{34} 35$ our result, showing decreased expression of BRCA2 with increased chance of developing hMDS, was probably not obtained by chance. New reports and in vitro models are necessary to confirm our associations.

LIG4 (DNA ligase 4) encodes a protein that is a DNA ligase which joins SSBs in a double-stranded polydeoxynucleotide in an ATP-dependent reaction. ${ }^{36}$ This protein is essential for V(D)J recombination, generation of the $\mathrm{T}$ cell receptor, immunoglobulin molecules and DNA DSB repair through NHEJ. ${ }^{36}$ We were interested to detect low expression of LIG4 among patients with hMDS because deficiency of LIG4 has been associated with pancytopenia, combined immunodeficiency, cellular radiosensitivity, and recently, its mutation was associated with alterations of $\mathrm{T}$ and $\mathrm{B}$ cell counts with an increased percentage of memory cells and hypogammaglobulinaemia, ${ }^{37}$ all markers of immune dysregulation. Hypoplastic MDS is considered an 'autoimmune disorder' owing to the concept that $\mathrm{T}$ cells contribute to bone marrow failure and that $\mathrm{T}$ cell depleting agents, such as rabbit and equine antithymocyte globulin, are important options of treatment. ${ }^{32} 33$

Importantly, we also detected among all patients evaluated (not only patients with hMDS) that correlation with the LIG4 gene occurred most often. It was positively correlated with ATM, BRCA1, BRCA2 and XPC genes, which are linked to HR and NER. These correlations demonstrate the important intrinsic relations between single and double DNA strand breaks in MDS, reinforcing the suggestion that these genes are all related to MDS pathogenesis.

We detected an increased expression of XPC and XPA in hMDS. Damage to DNA single strand that occurs in the genome is recognised by the XPC and XPE protein complexes, which are specific components of the global genome NER system. $^{26} 38$ The DNA helix is opened by the XPB and XPD helixes of the repair, allowing damage verification by the XPA protein. $^{26}{ }^{38}$ So, one important cell signalling (XPC) and the 'check' (XPA) of NER are hyperactivated in hMDS. As expected, we also found that these two genes were also positively correlated. Using the Cutoff Finder biostatistical tool to discriminate the survival by Kaplan-Meier with log-rank post-test, we also found that patients with higher XPA $(>0.001674)$ expression had a shorter overall survival $(\mathrm{p}=0.019 ; \mathrm{HR}=3.23 ; 95 \% \mathrm{CI}$ 1.15 to 9.06). This method correlates the dichotomised biomarker with a binary outcome using logistic regression. ${ }^{9}$ This is the first report to demonstrate the importance of the singlestrand DNA repair system in MDS and these modifications may be the first step in genomic instability which, if not properly corrected, would predispose to DSBs and, consequently, chromosomal abnormalities.

When evaluating patients with hMDS, most researchers have focused on evaluation of immunological abnormalities. ${ }^{34-35} 39$ We show, for the first time, that genes related to DNA repair may also be associated with the pathogenesis of hMDS. Recently, Danjou et al, ${ }^{39}$ evaluated a large cohort of patients with MDS exploring 147954 single nucleotide polymorphisms localised in regions which display some degree of association 
with immunological disorders. One of the most significant results was related to the gene RTEL1, an ATP helicase implicated in telomere-length regulation, DNA repair and genomic instability. ${ }^{39}$ Of utmost importance, mutations in RTEL1 are responsible for nail dystrophy, mucosal leucoplasia and progressive bone marrow failure, the hallmark of MDS. ${ }^{39}$ The authors demonstrate the intrinsic association of immunological disorders and genes related to DNA repair, reinforcing our proposal that DNA repair genes may be intrinsically related to the pathogenesis of hMDS.

Our study has some limitations. Limitations due to sample size are common in scientific publications, as stated by Danjou et $a l^{39}$ and Gonçalves et $a l .{ }^{40}$ We found significant associations and correlations, but the number of cases evaluated was low and we cannot exclude the possibility that the absence of associations related to other genes might be explained by this factor. We must also emphasise that the number of cases with hMDS was low, only nine cases. Hypolastic MDS is a rare entity among cases of MDS- $<10 \%$ of cases-which makes it difficult to study large numbers.

We believe that the pathogenesis of hMDS is associated with an immune-mediated process, ${ }^{34}$ and also with the repair mechanism of DSB and SSB lesions. One important question arises: might the expression of these genes be new biomarkers of MDS? New reports are necessary to confirm or not our results.

\section{Take home messages}

- Previously, our group has shown that double and single DNA strand breaks are related to the pathogenesis of myelodysplastic syndrome (MDS).

- Our study determined that DNA repair gene expressions are positively correlated and work in a dependent manner as a cascade of events and may be related to the pathogenesis and prognosis of MDS.

- To the best of our knowledge, our study demonstrates for the first time that hypoplastic MDS is associated with an immune-mediated process, and also with the repair mechanism of double-and single-strand breaks.

\section{Handling editor Mary Frances McMullin.}

Contributors HLRJ, ARSM, RTGdO, MBC, IRF, DdPB, JCdS, SMMM and RFP designed the study. provided patient materials and were responsible for the collection and assembly of data. HLRJ, ARSM, RTGdO, MBC, IRF, DdPB, JCdS, SMMM and RFP performed the molecular procedures and analysed the data. All authors drafted and edited the manuscript and approved the final version of manuscript before publication.

Funding This study was conducted with partial support from the National Counsel of Technological and Scientific Development (CNPq) and Cearense Foundation for the Support of Scientific and Technological Development (FUNCAP).

Competing interests None declared.

Ethics approval The study was approved by the ethics committee of the Federal University of Ceara (No. 1.292.509) and conducted according to the Declaration of Helsinki.

Patient consent Obtained.

Provenance and peer review Not commissioned; externally peer reviewed.

\section{REFERENCES}

1 Greenberg PL. Synergistic interactions of molecular and clinical advances for characterizing the myelodysplastic syndrome. J Natl Compr Canc Netw 2015; 13:829-32.
2 Balleari E, Salvetti C, Del Corso L, et al. Age and comorbidities deeply impact on clinical outcome of patients with myelodysplastic syndrome. Leuk Res 2015;39:846-52.

3 Cazzola M, Della Porta MG, Travaglino E, et al. Classification and prognostic evaluation of myelodysplastic syndrome. Semin Oncol 2011;38:627-34.

4 Yue $\mathrm{Gl}$, Hao S, Fadare 0, et al. Hypocellularity in myelodysplastic syndrome is an independent factor which predicts a favorable outcome. Leuk Res 2008;32:553-8.

5 Vardiman JW, Thiele J, Arber DA, et al. The 2008 revision of the World Health Organization (WHO) classification of myeloid neoplasms and acute leukemia: rationale and important changes. Blood 2009;114:937-51.

6 Invernizzi R, Quaglia F, Porta MG. Importance of classical morphology in the diagnosis of myelodysplastic syndrome. Mediterr J Hematol Infect Dis 2015;7: e2015035.

7 Della Porta MG, Travaglino E, Boveri E, et al. Minimal morphological criteria for defining bone marrow dysplasia: a basis for clinical implementation of WHO classification of myelodysplastic syndromes. Leukemia 2015;29:66-75.

8 Bennett JM, Orazi A. Diagnostic criteria to distinguish hypocellular acute myeloid leukemia from hypocellular myelodysplastic syndromes and aplastic anemia: recommendations for a standardized approach. Haematologica 2009;94:264-8.

9 Schemenau J, Baldus S, Anlauf M, et al. Cellularity. characteristics of hematopoietic parameters and prognosis in myelodysplastic syndromes. Eur I Haematol 2015;95:181-9.

10 Budczies J, Klauschen F, Sinn BV, et al. Cutoff finder: a comprehensive and straight forward web application enabling rapid biomarker cutoff optimization. PLOS ONE 2012;7:e51862.

11 Brunning RD, Germing U. Myelodysplastic syndromes. In: Orazi A, Weiss LM, Foucar $\mathrm{K}$, et al. Neoplastic hematopathology. 3rd edn. Philadelphia: Lippinscott Williams \& Wilkins, 2014:1076-107.

12 Batista MD, Fernandes RL, Rocha MAD, et al. Pioderma gangrenoso bolhoso e síndrome mielodisplásica. An Bras Dermatol 2016;81:309-\$312.

13 Young NS, Calado RT, Scheinberg P. Current concepts in the pathophysiology and treatment of aplastic anemia. Blood 2006;108:2509-19.

14 Belli CB, Pinheiro RF, Bestach Y, et al. Myelodysplastic syndromes in South America: a multinational study of 1080 patients. Am J Hematol 2015;90:851-8.

15 Hoeijmakers JH. DNA damage, aging and cancer. N Engl J Med 2009;361:1475-85.

16 Mandal PK, Blanpain C, Rossi DJ. DNA damage response in adult stem cells: pathways and consequences. Nat Rev Mol Cell Biol 2011;12:198-202.

17 Malcovati L, Hellström-Lindberg E, Bowen D, et al. Diagnosis and treatment of primary myelodysplastic syndromes in adults. Recommendations from the European LeukemiaNet. Blood 2013;122:2943-64.

18 Ribeiro HL Jr, Oliveira RT, Maia AR, et al. ATM polymorphism is associated with low risk myelodysplastic syndrome. DNA Repair (Amst) 2013;12:87-9.

19 Ribeiro HL Jr, de Oliveira RTG, Maia AR, et al. Polymorphisms of DNA repair genes are related to the pathogenesis of myelodysplastic syndrome. Hematol Oncol 2015;33:220-8.

20 Ribeiro HL Jr, Soares Maia AR, Costa MB, et al. Influence of functional polymorphisms in DNA repair genes of myelodysplastic syndrome. Leuk Res 2016;48:62-72.

21 Greenberg PL, Tuechler H, Schanz J, et al. Revised international prognostic scoring system for myelodysplastic syndromes. Blood 2012;120:2454-65.

22 Thiele J, Kvasnicka HM, Facchetti F, et al. European consensus on grading bone marrow fibrosis and assessment of cellularity. Haematologica 2005;90:1128-32.

23 Chauffaille ML. Adding FISH to karyotype in myelodysplastic syndrome investigation diagnosis: are all questions answered? Leuk Res 2010;34:413-5.

24 Livak KJ, Schmittgen TD. Analysis of relative gene expression data using real time quantitative PCR and the 2(-Delta DeltaC(T)) method. Methods 2001;25:402-8.

25 Kasparek TR, Humphrey TC. DNA double-strand break repair pathways: chromosomal rearrangements and cancer. Semin Cell Dev Biol 2011;22:886-97.

26 Alekseev $S$, Coin F. Orchestral maneuvers at the damaged sites in nucleotide excision repair. Cell Mol Life Sci 2015;72:2177-86.

27 Belli M, Sapora 0, Tabocchini MA. Molecular targets in cellular response to ionizing radiation and implications in space radiation protection. J Radiat Res 2002;43:13-19.

28 Friedenson $B$. The BRCA1/2 pathway prevents hematologic cancers in addition to breast and ovarian cancers. BMC Cancer 2007;7:7-152.

29 Scardocci A, Guidi F, D'alou F, et al. Reduced BRCA1 expression due to promoter hyermethylation in therapy-related acute myeloid leukaemia. $\mathrm{Br} J$ Cancer 2006;95:1108-13.

30 Wang $\mathrm{K}, \mathrm{Ye} Y, \mathrm{Xu} Z$, et al. Interaction between BRCA1/BRCA2 and ATM/ATR associate with breast cancer susceptibility in a Chinese Han population. Cancer Genet Cytogenet 2010;200:40-6.

31 Bai X, Fu Y, Xue H, et al. BRCA1 promoter hypermethylation in sporadic epithelial ovarian carcinoma: association with low expression of BRCA1, improved survival and co-expression of DNA methyltransferases. Oncol Lett 2014;7:1088-96.

32 Moro L, Arbini AA, Marra E, et al. Down-regulation of BRCA2 expression by collagen type I promotes prostate cancer cell proliferation. J Biol Chem 2005;280:22482-91.

33 Jeong JH, Jo A, Park $P$, et al. Brca2 deficiency leads to $T$ cell loss and immune dysfunction. Mol Cells 2015;38:251-8. 
34 Calado RT. Immunologic aspects of hypoplastic myelodysplastic syndrome. Semin Oncol 2011;38:667-72.

35 Serio B, Risitano A, Giudice V, et al. Immunological derangement in hypocellular myelodysplastic syndromes. Transl Med UniSa 2014;4:31-42.

36 Lieber MR. The mechanism of human nonhomologous DNA end joining. J Biol Chem 2008:283:1-5.

37 Felgentreff $\mathrm{K}$, Baxi SN, Lee YN, et al. Ligase-4 deficiency causes distinctive immune abnormalities in asymptomatic individuals. J Clin Immunol 2016;36:341-53.
38 Iyama T, Wilson DM. DNA repair mechanisms in dividing and non-dividing cells. DNA Repair (Amst) 2013;12:620-36.

39 Danjou F, Fozza C, Zoledziewska M, et al. A genome-wide association study by ImmunoChip reveals potential modifiers in myelodysplastic syndromes. Exp Hematol 2016;44:1034-8.

40 Gonçalves AC, Alves R, Baldeiras I, et al. Genetic variants involved in oxidative stress, base excision repair, DNA methylation, and folate metabolism pathways influence myeloid neoplasias susceptibility and prognosis. Mol Carcinog 2017;56:130-48. 


\section{$\mathrm{JCP}$}

DNA repair gene expressions are related to bone marrow cellularity in myelodysplastic syndrome

Howard L Ribeiro, Jr, Allan Rodrigo S Maia, Roberta Taiane G de Oliveira, Marília Braga Costa, Izabelle Rocha Farias, Daniela de Paula Borges, Juliana Cordeiro de Sousa, Silvia Maria M Magalhães and Ronald F Pinheiro

J Clin Pathol published online May 29, 2017

Updated information and services can be found at:

http://jcp.bmj.com/content/early/2017/05/28/jclinpath-2016-204269

\section{These include:}

References This article cites 39 articles, 9 of which you can access for free at: http://jcp.bmj.com/content/early/2017/05/28/jclinpath-2016-204269 \#BIBL

Email alerting service

Receive free email alerts when new articles cite this article. Sign up in the box at the top right corner of the online article.

\section{Notes}

To request permissions go to:

http://group.bmj.com/group/rights-licensing/permissions

To order reprints go to:

http://journals.bmj.com/cgi/reprintform

To subscribe to BMJ go to:

http://group.bmj.com/subscribe/ 